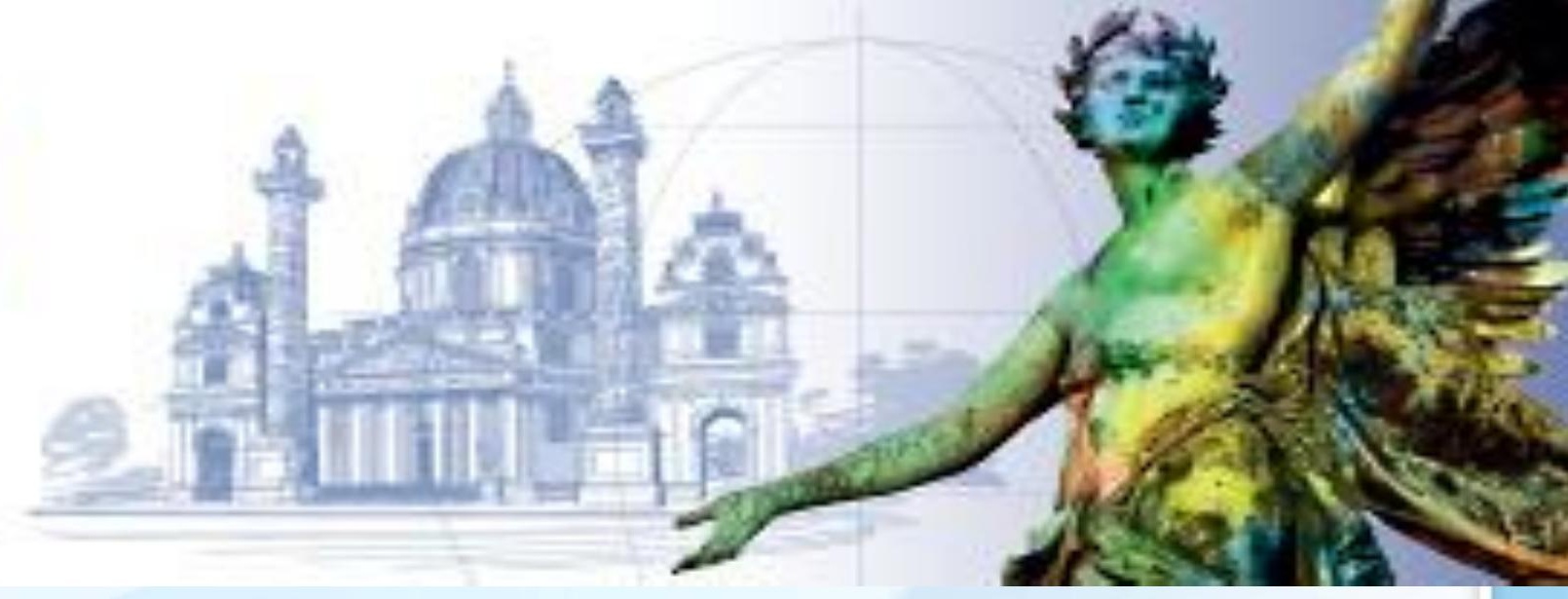

\title{
THE END-OF-LIFE CARE EXPERIENCE OF A TERMINAL OVARIAN CANCER PATIENT WITH HOSPICE CARE
}

\section{Tzu-Hui Hsu}

Shin Kong Wu Ho-Su Memorial Hospital, Nursing department, Taipei, Taiwan R.O.C.

\section{Introduction}

An 48 years old woman was diagnosed with ovarian cancer in 2014 and received regular chemotherapy. Unfortunately, Liver and Colon metastasis were found in January 2017 with symptoms of pain, ascites, jaundice, edema and other symptoms. The terminal stage symptoms are difficult to control, and the condition is getting worse. She did not have family members during hospitalization and she felt very lonely and hopeless. She divorced after giving birth to her daughter and her daughter was raised by her ex-husband. She silently cared for her daughter, but never met her. She worried about her daughter the most. She wanted to apologize to her because she thought she did not being a good mother, which is the greatest regret in her life.

\section{Objectives}

The purpose of this article was to present an end-of-life hospice care experience with a middle-aged woman who had a diagnosis of terminal ovarian cancer.

\section{Methods}

After establishing a good relationship with the patient and having many meetings with the medical team, she signed a DNR consent form and accepted hospice care. Assisted by doctors and nurses, social workers, psychologists and clinical Buddhist chaplain and other hospice-palliative multidisciplinary interventions. Through the intervention of analgesics, essential oils and aromatic massages, she relieved her pain and edema. The medical team accompanied her to listen to her wishes and find her daughter to meet her at the hospital. We encourage her to express the desire to meet her daughter and thank or apologize to each other.

\section{Results}

The case and her daughter had their first Mother's Day. The daughter also wrote a card of blessings for her. Under the precious and beautiful memories, the case also showed no regrets in life. The patient finally passed away in the company of her daughter in a dignified, peaceful and painless manner. Her daughter thanked us for allowing her to accompany her mother and express her love before her mother died.

\section{Conclusions}

The multidisciplinary team of hospice doesn't only take care of the individual physical symptoms, but also considers the needs of the psychosocial and spiritual needs to reach the whole person, the whole family, team, and community. Good quality of death and doesn't leave life's imperfections is the goal of our team.

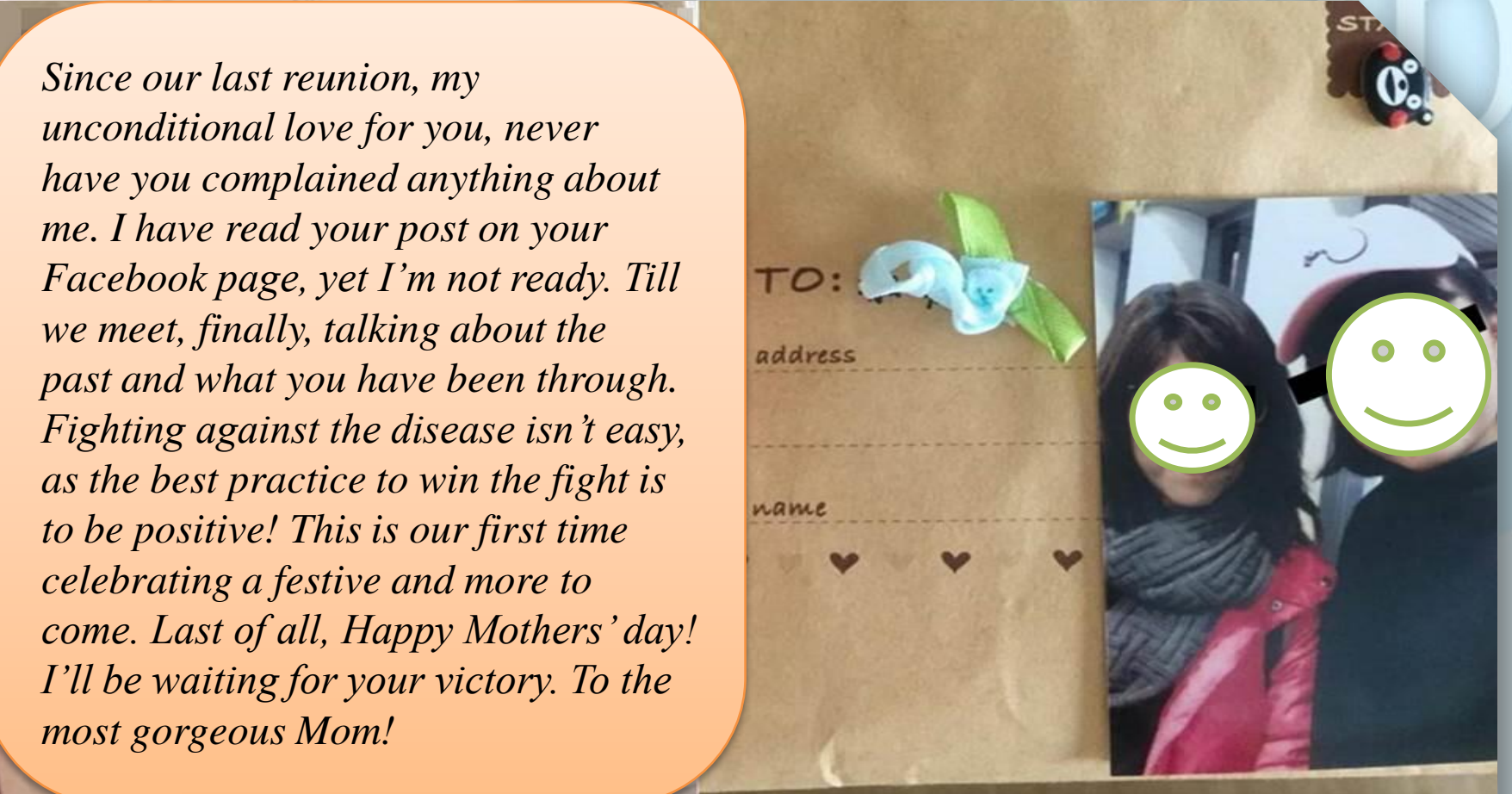

The card from her daughter before mother's day

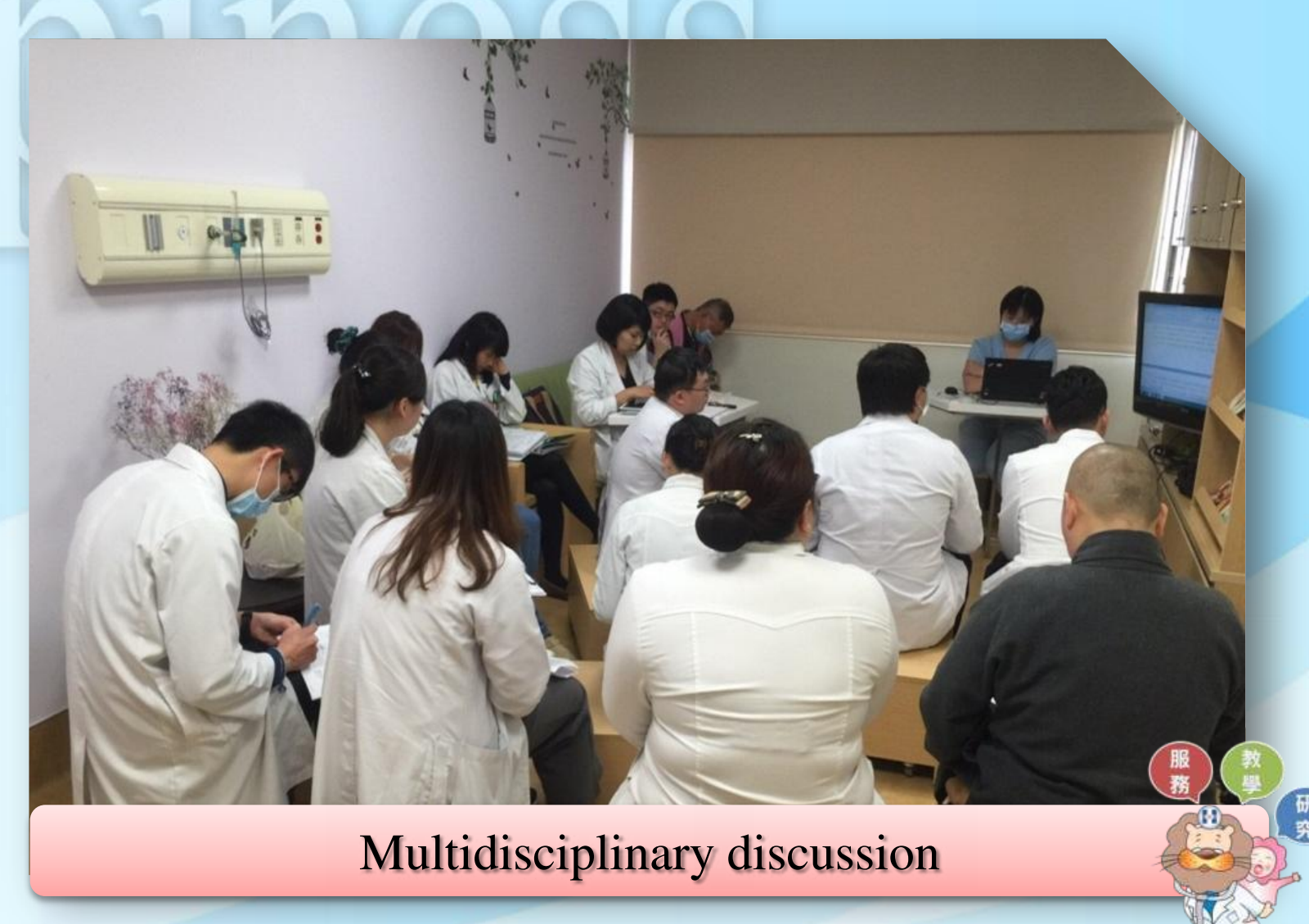

